\title{
EFECTO DEL ETILENO SOBRE EL ACC Y ACC OXIDASA EN LA MADURACION DE PAPAYA 'MARADOL'
}

\section{ETHYLENE EFFECT ON ACC CONTENT AND ACC OXIDASE DURING RIPENING OF 'MARADOL' PAPAYA}

\author{
Javier De la Cruz*, Gilber Vela, Lidia Dorantes y Hugo S. García
}

UNIDA, Instituto Tecnológico de Veracruz. M. A. de Quevedo 2779. 91897, Veracruz, Ver. Tel. (229)934-5701, 934-1469, 934-1478 ext. 115; fax, ext. 201

* Autor para correspondencia (jdlcruz@itver.edu.mx)

\section{RESUMEN}

Frutos de papaya 'Maradol' (Carica papaya L.) fueron tratados con etileno en aire sintético $\left(0,100,300\right.$ y $\left.500 \mu \mathrm{L} \mathbf{L}^{-1}\right)$ en contenedores de fibra de vidrio a diferentes tiempos de exposición $(8$, 16 y $24 \mathrm{~h}$ ). Después del tratamiento, los frutos fueron transferidos para su maduración a temperatura ambiente $\left(25^{\circ} \mathrm{C}\right)$. Los análisis efectuados en cada tratamiento fueron: firmeza, azúcares reductores, sólidos solubles, acidez titulable, color de cáscara y pulpa (Hue), velocidad de producción de etileno (VPE), contenido de ácido 1aminociclopropano-1-carboxílico (ACC) y actividad de la enzima formadora de etileno (ACC oxidasa). Los resultados indicaron que el primer cambio notable fue el color en la cáscara (amarillo) y en la pulpa (naranja), típicos en un fruto listo para el consumo. Los frutos expuestos a $500 \mu \mathrm{L} \mathrm{L}^{-1}$ de etileno por 16 y $24 \mathrm{~h}$ mostraron un pico climatérico un día después del tratamiento, mientras que los frutos expuestos por solamente $8 \mathrm{~h}$ mostraron su pico climatérico 2 d después de la exposición al etileno. Las papayas expuestas a $500 \mu \mathrm{L}$ $L^{-1}$ de etileno por 16 y 24 h produjeron bajos valores de Hue en menos tiempo que el testigo, y su contenido de ACC aumentó a 2.7 nmol $\mathrm{g}^{-1} \mathrm{~h}^{-1}$, la actividad de la ACC oxidasa a $3 \mathrm{~nL} \mathrm{~g}^{-1} \mathrm{~h}^{-1}$, y la velocidad de producción de etileno (VPE) a $24 \mathrm{~nL} \mathrm{~g}^{-1} \mathrm{~h}^{-1}$. Estas condiciones permitieron que se alcanzaran valores de firmeza de 5.2 kgf cm $\mathrm{cm}^{-2} 12 \%$ de sólidos solubles a los $6 \mathrm{~d}$ a $25^{\circ} \mathrm{C}$. El contenido de azúcares reductores, valores de $\mathrm{pH}$ y la acidez no mostraron diferencias significativas $(P>0.05)$ entre tratamientos. Los frutos testigo alcanzaron valores similares después de $8 \mathrm{~d}$ de maduración directa. Los resultados sugieren que es posible acelerar la maduración de papaya 'Maradol' de 8 a 3 d por exposición a atmósferas con etileno.

Palabras clave: Carica papaya, ACC, ACC oxidasa, etileno.

\section{SUMMARY}

'Maradol' papaya (Carica papaya L.) fruits were subjected to atmospheres containing certified mixtures of synthetic air and ethylene $\left(0,100,300\right.$ and $\left.500 \mu \mathrm{L} \mathrm{L}^{-1}\right)$ in fiberglass containers for different periods $(8,16$ and $24 \mathrm{~h})$. After exposure, fruits were transferred to ambient conditions $\left(25^{\circ} \mathrm{C}\right)$ for ripening. The analyses performed on each treatment were: firmness, soluble solids content, reducing sugars content, titratable acidity, peel and flesh color (Hue), ethylene production rate (EPR), 1-aminocyclopropane-1carboxylic acid (ACC) content and ethylene-forming enzyme (ACC oxidadese) activity. Results showed that the first noticeable change in fruits was the yellow and red color turning in peel and flesh respectively, both typical of a fully ripe and ready-to-eat-papaya fruit. Fruits exposed to $500 \mu \mathrm{L} \mathrm{L}^{-1}$ of ethylene for 16 and $24 \mathrm{~h}$ showed a climacteric peak one day after treatment, while fruits exposed for only $8 \mathrm{~h}$ displayed their climacteric peak $2 \mathrm{~d}$ after ethylene exposure. Papayas treated for 16 and $24 \mathrm{~h}$ developed very low Hue values in a shorter time then the control, and their ACC content increased to $2.7 \mathrm{nmol} \mathrm{g}^{-1} \mathrm{~h}^{-1}$. ACC oxidase activity also increased to 3 $\mathrm{nL} \mathrm{g}^{-1} \mathrm{~h}^{-1}$, and EPR reached $24 \mathrm{~nL} \mathrm{~g}^{-1} \mathrm{~h}^{-1}$. This set of conditions allowed fruits to reach firmness values of $5.2 \mathrm{kgf} \mathrm{cm}^{-2}$ and $12 \%$ of soluble solids after $6 \mathrm{~d}$ at $25{ }^{\circ} \mathrm{C}$. Reducing sugars content and percent age of titratable acidity were not different $(P>0.05)$ between treatments. Similar values were found in control fruits after $8 \mathrm{~d}$ at normal ripening conditions. Results suggest that it is possible to shorten ripening of 'Maradol' papaya fruit from 8 to $3 \mathrm{~d}$ after application of exogenous ethylene.

Index words: Carica papaya, ACC, ACC oxidase, ethylene.

\section{INTRODUCCIÓN}

La síntesis de etileno en el fruto se inicia a partir del aminoácido metionina (MET), que con acción de la enzima ACC sintasa es convertida a S-adenosilmetionina (SAM) por adición de adenina, mientras que la SAM es convertida a ácido carboxílico 1-amino-ciclo-propano (ACC). La producción de ACC es a menudo el punto control para la síntesis de etileno (Saltveit, 1999). Muchos factores intrínsecos y extrínsecos pueden afectar esta ruta (Yang, 1987).

La actividad de la ACC oxidasa se ha asociada con la integridad de membranas celulares (Abeles et al., 1992). Sin embargo, con la identificación del gen que codifica la ACC oxidasa en frutos de tomate, Lycopericum esculentum Mill. (Hamilton et al., 1991; Hamilton et al., 1990) se demostró que esta actividad es en realidad dependiente del ácido ascórbico y de iones $\mathrm{Fe}^{2+}$ como 
cofactores de la reacción (Ververidis y John, 1991), y se localiza mayormente en el citosol (Fernandez-Maculet et al., 1993). Estas observaciones han facilitado el aislamiento y la caracterización de la ACC oxidasa en tejidos de varias especies, lo que sugiere que la enzima puede actuar como una monooxigenasa que requiere ascorbato como donador de hidrógeno, oxígeno y $\mathrm{Fe}^{2+}$, según la siguiente reacción:

$$
\begin{gathered}
\mathrm{ACC}+\mathrm{O}_{2}+\text { Ascorbato } \stackrel{\mathrm{Fe}^{2+}, \mathrm{CO}_{2}}{\longrightarrow} \\
\mathrm{C}_{2} \mathrm{H}_{4}+\mathrm{CO}_{2}+\mathrm{HCN}+\text { Deshidroas corbato }+2 \mathrm{H}_{2} \mathrm{O}
\end{gathered}
$$

Así, el etileno se deriva a partir de los carbonos 2 y 3 del ACC. El $\mathrm{CO}_{2}$ se forma a partir del grupo carboxilo, el HCN a partir del carbono 1 y el grupo amino del ACC. El HCN es metabolizado a $\beta^{+}$-cianoalanina, la cual a su vez es convertida en asparagina o $\gamma$-glutamil- $\beta$-cianoalanina. Esta vía de destoxificación evita la acumulación del HCN, aun en plantas con altas velocidades de biosíntesis de etileno (Dong et al., 1992; Kende, 1993). En numerosos sistemas vegetales, la actividad in vivo de la ACC oxidasa es promovida por el $\mathrm{CO}_{2}$.

Las reservas de metionina en los tejidos de plantas son insuficientes para sostener las velocidades normales de producción de etileno, por lo que la metionina tiene que ser reciclada. El grupo metilo ( $\left.\mathrm{CH}_{3}-\mathrm{S}-\right)$ es liberado desde SAM como 5'-metiltioadenosina durante la formación de ACC. La conversión involucra la liberación de adenina, que posteriormente sufrirá una carboxilación para formar metionina. Una vez que la metionina está presente, el sistema funciona por el tiempo en que el suministro ATP sea adecuado. La porción del carbono 4 de la metionina, desde la cual se deriva el ACC, es suministrada por la porción de la ribosa a SAM vía el ATP, mientras que el $\mathrm{CH}_{3}-\mathrm{S}$ - de la metionina es conservado para la regeneración continua de la metionina (Abeles et al., 1992).

En el paso final, el ACC es oxidado por la enzima ACC oxidasa para formar etileno. Esta reacción de oxidación requiere la presencia de oxígeno, y bajos niveles de dióxido de carbono para activar a la enzima. Dado que el nivel de actividad de la ACC oxidasa usualmente se encuentra en exceso del nivel que necesitan muchos tejidos, esto puede reflejarse en un dramático incremento de actividad en maduración de frutos y en respuesta a la exposición de etileno (Saltveit, 1999).

La maduración acelerada de frutos tropicales con etileno exógeno, es una práctica frecuente que aprovecha la fisiología de frutos climatéricos para lograr una maduración rápida y reducir los costos de manejo y almacenamiento, y para lograr maduración homogénea. Esta tecnología permite colocar frutos en el mercado cuando la demanda es mayor y los costos son fácilmente absorbidos por los beneficios (Perez et al., 1998; Com Personal ${ }^{1}$ ). En sus recomendaciones para mantener la calidad postcosecha de papaya (Carica papaya L.) Kader (2002) reporta una tasa de producción de etileno entre 1 y $15 \mu \mathrm{L}$ de $\mathrm{C}_{2} \mathrm{H}_{4} \mathrm{~kg}^{-1} \mathrm{~h}^{-1}$ del fruto a $20{ }^{\circ} \mathrm{C}$ como temperatura óptima, así como una maduración más rápida y uniforme cuando los frutos son tratados con etileno exógeno a una concentración de $100 \mu \mathrm{L} \mathrm{L}^{-1}$ entre 20 y $25^{\circ} \mathrm{C}$.

El tratamiento con etileno previo al almacenamiento refrigerado de frutos de papaya representa una excelente alternativa, debido a que ese gas induce una maduración homogénea y permite almacenarlos sin pérdida de calidad, tal como sucede en un fruto madurado convencionalmente. De La Cruz et al. (2007) reportaron resultados benéficos de etileno en cuanto a maduración homogénea, cuando los frutos de papaya fueron tratados con $500 \mu \mathrm{L}$ $\mathrm{L}^{-1}$ de etileno exógeno durante $24 \mathrm{~h}$ a $25^{\circ} \mathrm{C}$, porque extendió a $17 \mathrm{~d}$ la vida útil de los frutos en almacenamiento refrigerado.

Dada la necesidad de generar información técnica acerca de la evolución de ACC, la actividad de ACC oxidasa y la velocidad de producción de etileno, así como de la respuesta del fruto a estos compuestos en cuanto a maduración, en este trabajo se propuso probar diferentes concentraciones de etileno y diferentes tiempos de exposición, que permitan una aplicación tecnológica al manejo postcosecha de la papaya 'Maradol'.

\section{MATERIALES Y MÉTODOS}

\section{Frutos y tratamientos}

Frutos frescos de papaya 'Maradol' fueron obtenidos del Campo Agrícola Experimental del Instituto Nacional de Investigaciones Forestales, Agrícolas y Pecuarias ubicado en Cotaxtla, Veracruz. Los frutos fueron seleccionados por su uniformidad en tamaño, forma y color, y después lavados y desinfectados con cloro (Cloralex ${ }^{\circledR}$ de 5.25 a $6 \%$ ). Los frutos tenían un color verde con $25 \%$ de amarillo al momento de la cosecha, firmes al tacto y un peso de 1500 a $1800 \mathrm{~g}$. Los frutos fueron divididos en 10 grupos de 100 unidades. Nueve grupos fueron expuestos a mezclas certificadas de gases que contenían 100, 300 ó $500 \mu \mathrm{L} \mathrm{L}^{-1}$ de etileno (AGA®) por 8, 16 ó $24 \mathrm{~h}$, en

\footnotetext{
1 Pérez A S, J C Cayuela, P Navarro (1998) Respuesta a la desverdización de nuevas variedades de mandarina temprana. In: Congreso Iberoamericano de Tecnología Postcosecha y Agroexportaciones. pp:53-54.
} 
tanques fabricados de fibra de vidrio con tapa de acrílico. Después del tratamiento se mantuvieron por un periodo hasta de $8 \mathrm{~d}$ a $25{ }^{\circ} \mathrm{C}$, durante el cual se les midieron las variables de respuesta. El último grupo (frutos testigo) se mantuvo directamente a $25{ }^{\circ} \mathrm{C}$ de almacenamiento y $\sin$ exposición a etileno.

\section{Variables de respuesta}

El contenido del ácido 1-aminociclopropano-1-carboxilico (ACC) y la actividad de la enzima ACC oxidasa se determinaron durante el almacenamiento a $25{ }^{\circ} \mathrm{C}$, de acuerdo con el método descrito por Lizada y Yang (1979). En cada caso se usó una curva estándar elaborada previamente. La velocidad de producción de etileno (VPE) se determinó en frutos colocados en pequeñas cámaras individuales de $\mathrm{PVC}$ de $6 \mathrm{~L}$ de capacidad (cámara de respiración) con sellado hermético, por $5 \mathrm{~h}$; transcurrido ese tiempo se extrajo una muestra del gas producido por la respiración de los frutos con una jeringa para cromatografía de gases, y se inyectó $1 \mathrm{~mL}$ de espacio de cabeza al cromatógrafo de gases (HP 5890 Series II ${ }^{\circledR}$ Avandale, PA, USA.) provisto con una columna Poraplot $\mathrm{Q}{ }^{\circledR}$ de $12 \mathrm{~m}$ de longitud y $0.30 \mathrm{~mm}$ de diámetro, bajo las siguientes condiciones: detectores TCD y FID conectados en serie, ambos a $250{ }^{\circ} \mathrm{C}$, horno a $80{ }^{\circ} \mathrm{C}$ e inyector a $150{ }^{\circ} \mathrm{C}$, con nitrógeno como gas acarreador a un flujo de $2 \mathrm{~mL} \mathrm{~min}^{-1}$ en la columna.

La firmeza se evaluó con un penetrómetro de frutos (IRC Force Gage ${ }^{\circledR}$, Norfolk, VA, USA.) provisto de una sonda cónica de $6 \mathrm{~mm}$ y de sensores en el rango de 0-5 a $0-12 \mathrm{~kg} f \mathrm{~cm}^{-2}$; el valor de firmeza se expresó como la fuerza requerida para que la punta cónica del penetrómetro se introdujera en la pulpa dividido por la unidad de área que ocupa la punta (NOM, 1982). El contenido de sólidos solubles (CSS) se determinó con un refractómetro de Abbe (Leica Mark II ${ }^{\circledR}$ Buffalo, NY, USA.) a $20{ }^{\circ} \mathrm{C}$, y el resultado se reportó como porciento (\%) de sólidos solubles (AOAC, 1990). El valor de $\mathrm{pH}$ se midió con un potenciómetro, de acuerdo con la AOAC (1990), y la acidez titulable (AT) se determinó en el jugo de los frutos mediante titulación con $0.1 \mathrm{~N} \mathrm{NaOH}$, con el método establecido por la AOAC (1990) y los resultados se expresaron como porcentaje de acido cítrico. El color se medió en la cáscara y en la pulpa de los frutos, con un colorímetro HunterLab (MiniScan ${ }^{\circledR}$ Resto, VA, USA.) mediante la escala $\mathrm{L} * \mathrm{a} * \mathrm{~b} *$.

Los datos obtenidos se analizaron conforme a un diseño estadístico completamente al azar en arreglo factorial $4 \mathrm{x}$ 3 x 8; el primer factor corresponde a cuatro concentraciones de etileno $\left(0,100,300\right.$ y $\left.500 \mu \mathrm{L} \mathrm{L}^{-1}\right)$, el segundo a tres tiempos de exposición $(8,16$ y 24 h) a las concentra- ciones mencionadas, y el tercero a $8 \mathrm{~d}$ de muestreo y almacenamiento. Cada muestreo se hizo por triplicado y dos réplicas del experimento. El análisis estadístico consistió en análisis de varianza y pruebas de intervalos múltiples de Duncan, con el paquete estadístico MINITAB ${ }^{\circledR}$ v.12.21 para Windows.

\section{RESULTADOS Y DISCUSIÓN}

La velocidad de producción de etileno (VPE) se midió en frutos expuestos a $100 \mu \mathrm{L} \mathrm{L}^{-1}$ de etileno, los cuales por $5 \mathrm{~d}$ no mostraron diferencias significativas entre los tratamientos (Figura 1). El contenido de ACC en la pulpa permaneció constante hasta $2 \mathrm{~d}$ después del tratamiento. La reducida actividad inicial de la ACC oxidasa provocó una acumulación del ACC en el tratamiento de 24 h; sin embargo, al quinto día la concentración disminuyó como consecuencia del aumento de la actividad de la ACC oxidasa y de la producción de etileno endógeno. Los frutos testigo mostraron su pico climatérico al séptimo día de almacenamiento, cuando ocurrió un cambio de color por maduración a $50 \%$ de amarillo. En frutos del testigo la VPE fluctuó de 2 a $19 \mathrm{~nL} \mathrm{~g}^{-1} \mathrm{~h}^{-1}$ hasta el pico climatérico, valores similares a los reportados previamente por Kader (1986) para papayas en maduración a $20{ }^{\circ} \mathrm{C}\left(1\right.$ a $15 \mathrm{~nL} \mathrm{~g}^{-1}$ $\left.\mathrm{h}^{-1}\right)$. En las papayas expuestas a $100 \mu \mathrm{L} \mathrm{L}^{-1}$ de etileno exógeno por $24 \mathrm{~h}$, la VPE varió de 2 a $18 \mathrm{~nL} \mathrm{~g} \mathrm{~h}^{-1}$ durante su almacenamiento. La actividad de la ACC oxidasa durante el pico climatérico cayó entre 1 y $1.25 \mathrm{~nL}$ $\mathrm{g}^{-1} \mathrm{~h}^{-1}$. El contenido de ACC en frutos expuestos por $16 \mathrm{y}$ $24 \mathrm{~h}$ al etileno, mostró su máximo entre 3 y 5 d de almacenamiento, y correspondió a 1.6 y $1.7 \mathrm{nmol} \mathrm{g}^{-1} \mathrm{~L}^{-1}$, respectivamente.

En tejidos expuestos a $300 \mu \mathrm{L} \mathrm{L}^{-1}$ de etileno durante 8, 16 y $24 \mathrm{~h}$, la VPE alcanzó sus mayores valores entre los días 2 y 5 posteriores al tratamiento, lo cual es seguramente debido al climaterio de los frutos, punto que también coincide con los mayores valores de ACC oxidasa (Figura 1). El contenido de ACC aumentó en los primeros $4 \mathrm{~d}$ para después decrecer de nuevo, debido al aumento en la actividad de la ACC oxidasa. Lizada (1993) encontró que la producción de etileno disminuye en frutos sobremaduros, por la menor actividad de la ACC oxidasa, y que su precursor el ACC se acumula cuando se pierde la integridad de la membrana. Así, la disminución en la producción de etileno se ha atribuido a la pérdida de actividad de la ACC oxidasa, al perderse la integridad de la membrana (Lizada 1993).

Los frutos expuestos $24 \mathrm{~h}$ al etileno mostraron el pico climatérico $1 \mathrm{~d}$ después del tratamiento, con valores cercanos a $16 \mathrm{~nL} \mathrm{~g}^{-1} \mathrm{~h}^{-1}$ (Figura 1). Bajo estas condiciones el pico climatérico se adelanta hasta por $4 \mathrm{~d}$ con respecto al 
grupo testigo. Las papayas que fueron tratadas con etileno por 8 y $16 \mathrm{~h}$ lograron un máximo de VPE de 23 y $12 \mathrm{~nL}$ $\mathrm{g}^{-1} \mathrm{~h}^{-1}$, respectivamente a los $5 \mathrm{~d}$ de almacenamiento. El contenido de ACC de las papayas tratadas por $24 \mathrm{~h}$ presentaron un máximo de $2 \mathrm{nmol} \mathrm{g}^{-1} \mathrm{~h}^{-1}$ en el punto de mayor producción de etileno, mientras que la actividad de la ACC oxidasa fue de $1.3 \mathrm{~nL} \mathrm{~g}^{-1} \mathrm{~h}^{-1}$ en el primer día y de $3 \mathrm{~nL} \mathrm{~g}^{-1} \mathrm{~h}^{-1}$ el segundo. Este incremento en la actividad enzimática en papayas con tratamiento con etileno fue similar al reportado por Dong et al. (1992) para manzanas (Malus domestica Borkh.) tratadas con etileno, con incrementos en la actividad de ACC oxidasa como consecuencia del tratamiento con una apropiada concentración de etileno.

El comportamiento de la VPE, del contenido de ACC y de la actividad de la ACC oxidasa de frutos almacenados después de haber sido tratados con $500 \mu \mathrm{L} \mathrm{L}^{-1}$ de etileno, se describen en la Figura 1. Los frutos que fueron expuestos al etileno por 16 y $24 \mathrm{~h}$ mostraron su pico climatérico $1 \mathrm{~d}$ después del tratamiento, mientras que en las papayas que fueron expuestas por $8 \mathrm{~h}$, el pico apareció $2 \mathrm{~d}$ después del tratamiento. Esta tendencia coincide con la actividad de la ACC oxidasa, que mostró su máximo durante los primeros $3 \mathrm{~d}$ de almacenamiento. Es posible notar que durante los dos primeros días el contenido de ACC fue bajo y después aumentó, lo cual es atribuible a la elevada actividad de la ACC oxidasa, con la consecuente conversión a etileno. La posterior acumulación de ACC también coincide con menor actividad de la enzima productora de etileno, que es común cuando los frutos entran a la etapa posterior a la madurez (senescencia), que debilita la integridad de las membranas celulares. La integridad de las membranas es necesaria para que la enzima permanezca activa.

Papayas expuestas por $24 \mathrm{~h}$ a $500 \mu \mathrm{L} \mathrm{L}^{-1}$ de etileno alcanzaron una VPE de $24 \mathrm{~nL} \mathrm{~g}^{-1} \mathrm{~h}^{-1}$ en el pico climatérico, con un aumento en el contenido del ACC a $2.7 \mathrm{nmol} \mathrm{g}^{-1} \mathrm{~h}^{-1}$ y una actividad de la ACC oxidasa de 3 $\mathrm{nL} \mathrm{g}^{-1} \mathrm{~h}^{-1}$ (Figura 1). Este aumento en los valores es consistente con el reporte de Tonutti et al. (1993), quienes encontraron que el tratamiento de frutos climatéricos con una concentración ideal de etileno exógeno, estimula la acumulación de ACC y la actividad de la ACC oxidasa. Frutos expuestos a $500 \mu \mathrm{L} \mathrm{L}^{-1}$ por $16 \mathrm{~h}$ mostraron una reducción en estos valores, mientras que aquellos sujetos a $8 \mathrm{~h}$ de tratamiento produjeron menores valores de VPE, ACC y actividad de la ACC oxidasa.

El etileno sólo es necesario para iniciar el proceso de maduración y la aceleración del proceso depende de la interacción entre el tiempo de exposición y la concentración del etileno en la atmósfera. Una vez que la madura- ción se inicia, la respuesta no es proporcional a la presencia de etileno, y se requiere una atmósfera rica en oxígeno para completar el proceso. Saltveit (1999) sugiere que en la ruta de biosíntesis del etileno, cuando la ACC sintasa es inhibida el ACC no es producido y se acumula parte de la SAM en el tejido, la cual se transforma en el ácido 1-(malonilamínico) ciclopropano-1-carboxilico (MACC). Este es un compuesto sin actividad biológica producido por la ACC maloniltransferasa.
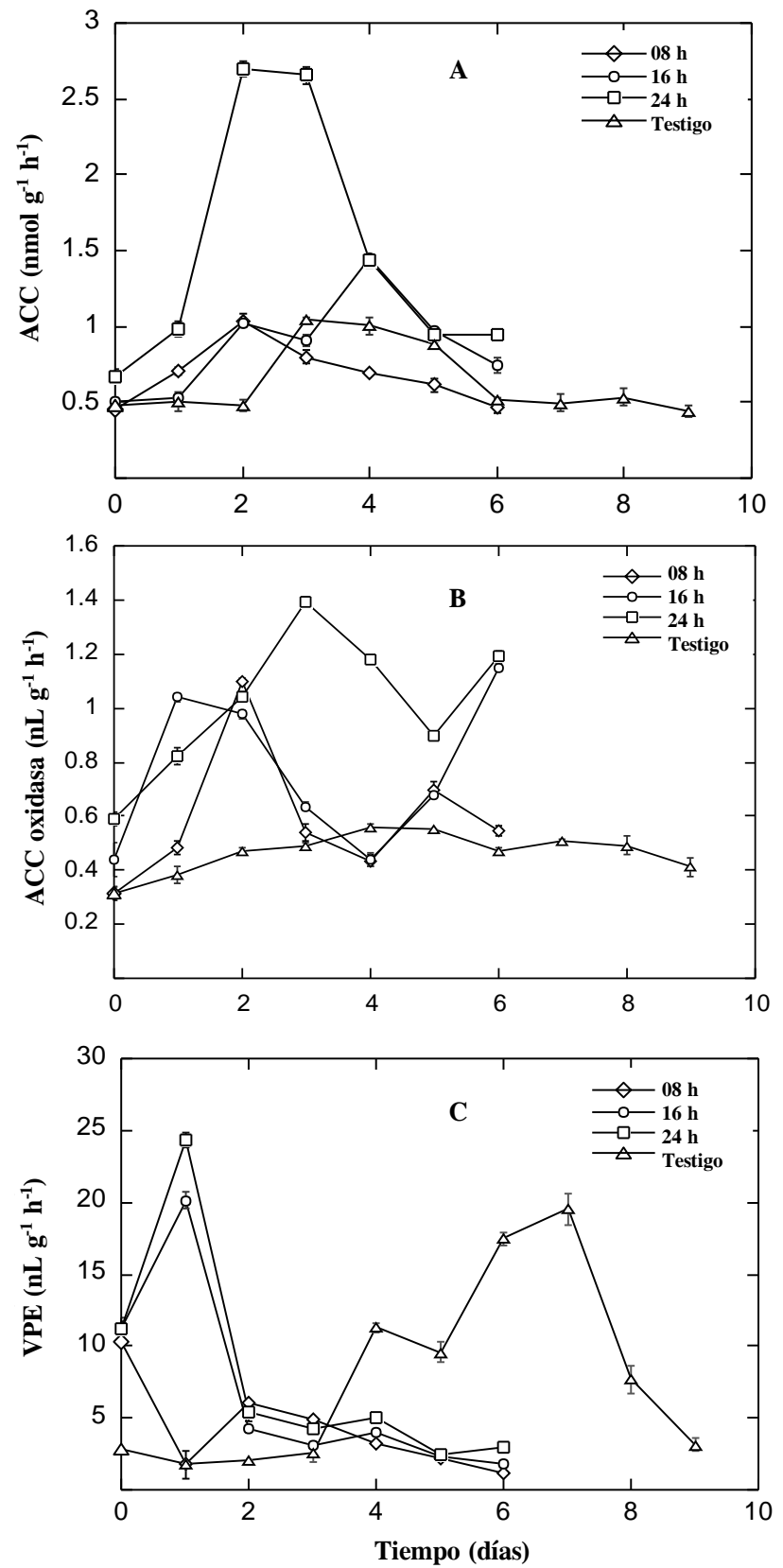

Figura 1. Promedios de ACC (A), ACC oxidasa (B) y VPE (C) en papaya 'Maradol' tratada con $500 \mu \mathrm{g} \mathrm{L} \mathrm{L}^{-1}$ de etileno durante 8, $16 \mathrm{y}$ $24 \mathrm{~h}$, y luego maduradas a $25{ }^{\circ} \mathrm{C}$. ACC = ácido 1aminociclopropano-1-carboxílico; VPE = velocidad de producción de etileno. 
De esta forma, la malonilación de la ACC puede disminuir los niveles de ACC en el tejido y puede ser una vía importante en la regulación del proceso de maduración en frutos. Por su parte, Abeles et al. (1992) encontraron que durante la biosíntesis de etileno en frutos tratados con etileno exógeno, si la cantidad del etileno aplicado es muy elevada y los tiempos de exposición son mayores a 30 min, se pueden producir condiciones de anaerobiosis y la biosíntesis de etileno puede parar parcialmente, ya que la anaerobiosis inactiva a la ACC oxidasa.

Al comparar la VPE de los frutos expuestos a diferentes concentraciones de etileno $\left(100,300\right.$ y $\left.500 \mu \mathrm{L} \mathrm{L}^{-1}\right)$ durante $24 \mathrm{~h}$, se pudo observar una marcada diferencia estadística $(\mathrm{P}<0.05)$ entre tratamientos (Cuadro 1$)$ y el grupo testigo. De igual forma, entre los frutos expuestos a la misma concentración de etileno durante $24 \mathrm{~h} \mathrm{y}$ el testigo no mostraron diferencias estadísticas suficientes en la actividad ACC oxidasa y en la concentración de ACC monitoreada durante la maduración.

Estos resultados demuestran el efecto del etileno exógeno en inducir la maduración, debido a que el etileno estimula la actividad de las enzimas involucradas en el proceso de maduración, como poligalacturonasa (PG), pectinmetilesterasa (PME), ACC sintasa y ACC oxidasa. Consecuentemente el etileno induce una maduración acelerada, sin cambios sensoriales en comparación con los frutos madurados normalmente. El tratamiento que mejor resultado presentó es el de $500 \mu \mathrm{L} \mathrm{L}^{-1}$ durante 24 a $48 \mathrm{~h}$ de exposición, que logró reducir de $8 \mathrm{~d}$ en la maduración normal a $3 \mathrm{~d}$ bajo esas condiciones.

La textura (Figura 2) disminuyó rápidamente durante los primeros $3 \mathrm{~d}$ de la maduración a $25{ }^{\circ} \mathrm{C}$ en todos los tratamientos, con los valores más bajos en los frutos expuestos durante $24 \mathrm{~h}$ a $500 \mu \mathrm{L} \mathrm{L}^{-1}$ de etileno. Las papayas expuestas a $300 \mu \mathrm{L} \mathrm{L}^{-1}$ de etileno tuvieron valores más bajos de textura que los expuestos a $500 \mu \mathrm{L}$ $\mathrm{L}^{-1}$, pero no más bajos que los otros tratamientos. Las papayas tratadas con $100 \mu \mathrm{L} \mathrm{L}^{-1}$ de etileno mostraron una tendencia similar a los frutos testigo. Estos frutos alcanzaron aproximadamente un séptimo del valor de firmeza que los frutos expuestos a $500 \mu \mathrm{L} \mathrm{L}^{-1}$, a $3 \mathrm{~d}$ después del tratamiento. Las papayas expuestas a $500 \mu \mathrm{L}$ $\mathrm{L}^{-1}$ por 16 ó $24 \mathrm{~h}$ no mostraron diferencias significativas, pero en ambos casos se registró reblandecimiento de tejidos.

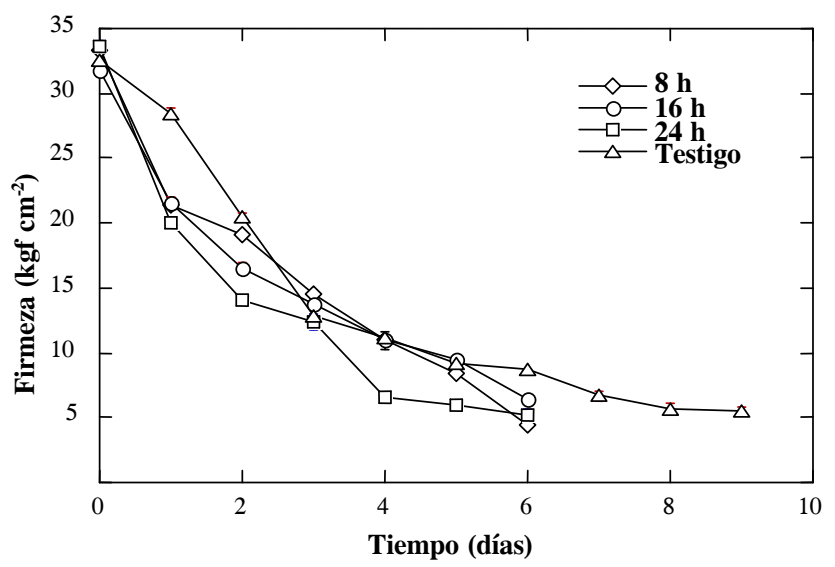

Figura 2. Efecto de la maduración acelerada a $25{ }^{\circ} \mathrm{C}$ en atmósfera modificada con $500 \mu \mathrm{L} \mathrm{L}^{-1}$ de etileno por 8, 16 ó 24 h de exposición, sobre la firmeza del fruto de papaya 'Maradol'.

El ablandamiento del tejido de la pulpa se debe a enzimas hidrolíticas que degradan la pared celular, pero no el almidón, el cual no es sintetizado durante la ontogenia (Paull y Chen, 1983). Se han documentado variaciones en la velocidad de ablandamiento en cultivares de papaya y en particular en la velocidad en la que la pulpa pierde toda su textura y su turgencia celular (Paull y Chen, 1983). La pectinmetilestearasa (PME) tiene un efecto limitado en el ablandamiento de la pared celular, pues sólo causa desmetilación parcial de la cadena del acido poligalacturonico, lo cual sirve para permitir la actividad de la poligalacturonasa (PG). La caída en firmeza es una consecuencia del proceso de maduración, que es un fenómeno complejo.

Tabla 1. Velocidad de producción de etileno (VPE) de los frutos almacenados a $25{ }^{\circ} \mathrm{C}$ posterior al tratamiento con etileno.

\begin{tabular}{lcccc}
\hline \multirow{2}{*}{$\begin{array}{l}\text { Tiempo almacenamiento posterior } \\
\text { al tratamiento con etileno (d) }\end{array}$} & \begin{tabular}{c} 
Velocidad de producción de etileno (VPE) \\
\cline { 2 - 5 }
\end{tabular} & $\begin{array}{c}\text { Tratamiento 2 } \\
\left(100 \mu \mathrm{L} \mathrm{L}^{-1} \mathrm{de} \text { etileno }\right)\end{array}$ & $\begin{array}{c}\text { Tratamiento 3 } \\
\left(300 \mu \mathrm{L} \mathrm{L}^{-1} \mathrm{de} \text { etileno }\right)\end{array}$ & Testigo \\
\hline 1 & $2.07 \pm 0.06 \mathrm{a}$ & $5.94 \pm 0.09 \mathrm{~b}$ & $11.19 \pm 0.034 \mathrm{c}$ & $2.89 \pm 0.03 \mathrm{~d}$ \\
2 & $2.41 \pm 0.01 \mathrm{a}$ & $5.60 \pm 0.047 \mathrm{~b}$ & $24.33 \pm 0.03 \mathrm{c}$ & $1.77 \pm 0.011 \mathrm{~d}$ \\
3 & $2.95 \pm 0.013 \mathrm{a}$ & $7.48 \pm 0.01 \mathrm{~b}$ & $5.46 \pm 0.005 \mathrm{c}$ & $2.02 \pm 0.01 \mathrm{~d}$ \\
4 & $2.40 \pm 0.005 \mathrm{a}$ & $9.72 \pm 0.003 \mathrm{~b}$ & $4.31 \pm 0.16 \mathrm{c}$ & $2.52 \pm 0.01 \mathrm{~d}$ \\
5 & $5.80 \pm 0.005 \mathrm{a}$ & $10.89 \pm 0.001 \mathrm{~b}$ & $5.04 \pm 0.001 \mathrm{c}$ & $11.20 \pm 0.19 \mathrm{~d}$ \\
6 & $8.27 \pm 0.005 \mathrm{a}$ & $19.23 \pm 0.231 \mathrm{~b}$ & $2.46 \pm 0.006 \mathrm{c}$ & $9.59 \pm 0.011 \mathrm{~d}$ \\
7 & $18.68 \pm 0.01 \mathrm{a}$ & $11.53 \pm 0.028 \mathrm{~b}$ & $2.94 \pm 0.032 \mathrm{c}$ & $17.51 \pm 0.005 \mathrm{~d}$ \\
\hline
\end{tabular}

Letras diferentes en la misma fila muestran diferencias estadísticas significativas (Duncan, 0.05) 
La pérdida de estructura celular involucra la reducción del tamaño de las cadenas de polímetros que integran la pared celular (almidón, pectinas, celulosa y hemicelulosa), por efecto de la celulasa, pectinasa y otras hidrolasas asociadas a la maduración y cuya expresión se acelera con la presencia de etileno exógeno (Marangoni et al., 1995). Según Pantástico (1979), el aumento de la actividad de las enzimas pécticas es la razón principal del ablandamiento de la pulpa en frutos. Las substancias pécticas están localizadas principalmente en la pared celular y en la lámina media, actúan como material aglutinante, y disminuyen durante la maduración. Se ha propuesto que la calidad de la papaya fresca o procesada está determinada por su firmeza (Chan-Jr et al., 1981).

La evolución de los sólidos solubles (CSS) mostró un aumento gradual. Este efecto fue más pronunciado en frutos expuestos a $500 \mu \mathrm{L} \mathrm{L}^{-1}$ (Figura 3), lo que puede deberse a la presencia del etileno exógeno que activó el metabolismo de conversión de almidón a azúcares, como fue reportado por Kader (1986) para frutos climatéricos. Las papayas tratadas con $500 \mu \mathrm{L} \mathrm{L}^{-1}$ de etileno durante 16 y $24 \mathrm{~h}$ alcanzaron valores cercanos a $12 \%$ de concentración de pólidos solubles durante los 4 d siguientes, mientras que los frutos testigo y los de los demás tratamientos los alcanzaron hasta el octavo día. Los frutos tratados con $100 \mu \mathrm{L} \mathrm{L}^{-1}$ de etileno no mostraron diferencias significativas con respecto a los testigos, lo que sugiere que tal concentración no es suficiente para promover la maduración acelerada. De acuerdo con Chan-Jr (1979), la cantidad de azúcares que son sintetizados en post-cosecha es sólo de 3 a $4 \%$; este bajo incremento en sólidos solubles se debe a la conversión del almidón que se produce durante la ontogenia para dar lugar a azúcares simples en la misma etapa; el mismo autor sugiere que la producción de sacarosa a partir del almidón es mínima, pero que contribuye al aumento marginal de los sólidos solubles después de la cosecha al degradarse a azúcares simples.

La acidez titulable de los frutos (datos no mostrados) sometidos a maduración acelerada en atmósferas con etileno en todos los tratamientos presentó el mismo patrón, y sin diferencias $(\mathrm{P}>0.05)$ entre los tratamientos con etileno y el grupo testigo; tampoco hubo cambio significativo entre el valor inicial y final durante el tiempo de almacenamiento en todos los tratamientos. En la evolución del $\mathrm{pH}$ (datos no mostrados) durante el experimento, no se detectaron cambios significativos en los tratamientos, resultados que son concordantes con el comportamiento de la acidez titulable en los frutos.

Los azúcares reductores determinados del jugo extraído de la pulpa de los frutos (datos no mostrados), tampoco mostraron diferencias significativas entre los frutos tratados y los testigos. Chan-Jr (1979) reportó que la papaya sintetiza la totalidad de sus azúcares reductores durante su desarrollo. En estas etapas el almidón se convierte a sacarosa y posteriormente a glucosa y fructosa, hexosas que se acumulan como productos del metabolismo; según el mismo autor, en algunos cultivares de papaya puede existir un ligero incremento después de la cosecha debido a que se sintetiza cierta cantidad de sacarosa en la etapa previa al corte, pero el incremento es muy bajo y muchas veces no significativo. Se ha sugerido que el bencil isotiocianato encontrado en el fruto verde maduro, puede ser responsable del sabor amargo en vino de papaya y puede perturbar la sensación de dulzor del fruto verde (Wills y Widjanarko, 1995).

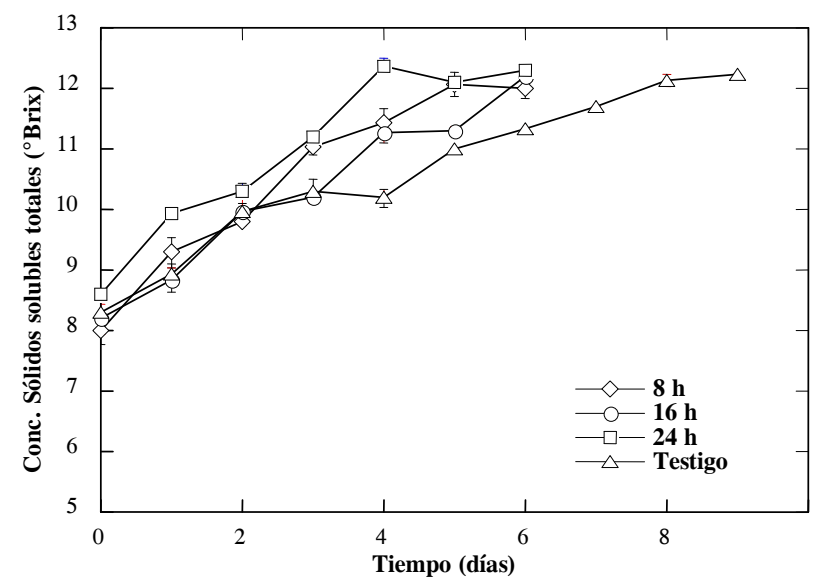

Figura 3. Efecto de la maduración acelerada a $25{ }^{\circ} \mathrm{C}$ en atmósfera modificada con $500 \mu \mathrm{L} \mathrm{L}^{-1}$ de etileno por 8, 16 ó 24 horas de exposición, sobre el contenido de sólidos solubles en frutos de papaya 'Maradol'.

El color de la piel y la pulpa fue medido por el ángulo Hue. Los frutos expuestos a 500 y $300 \mu \mathrm{L} \mathrm{L}^{-1}$ de etileno redujeron los valores de Hue en menor tiempo, mientras que los tratados con $500 \mu \mathrm{L} \mathrm{L}^{-1}$ lograron menores valores después de una exposición por $24 \mathrm{~h}$ (Figuras 4 y 5). Las papayas tratadas con $100 \mu \mathrm{L} \mathrm{L}^{-1}$ de etileno a diferentes tiempos mostraron un descenso lento en los valores de Hue comparados con el grupo testigo, pero no mayor que los otros tratamientos, mientras que las papayas expuestas a $500 \mu \mathrm{L} \mathrm{L}^{-1}$ por 16 ó $48 \mathrm{~h}$ alcanzaron el mismo valor de Hue al tercer día, que los frutos testigo alcanzaron al séptimo día. Salveit (1999) encontró que en las papayas expuestas a $100 \mu \mathrm{L} \mathrm{L}^{-1}$ de etileno se estimula el proceso de maduración, a juzgar por el color amarillo de la cáscara, la síntesis de carotenoides y el ablandamiento de la pulpa, ya que el etileno estimula la degradación de la clorofila y la síntesis de carotenoides. 


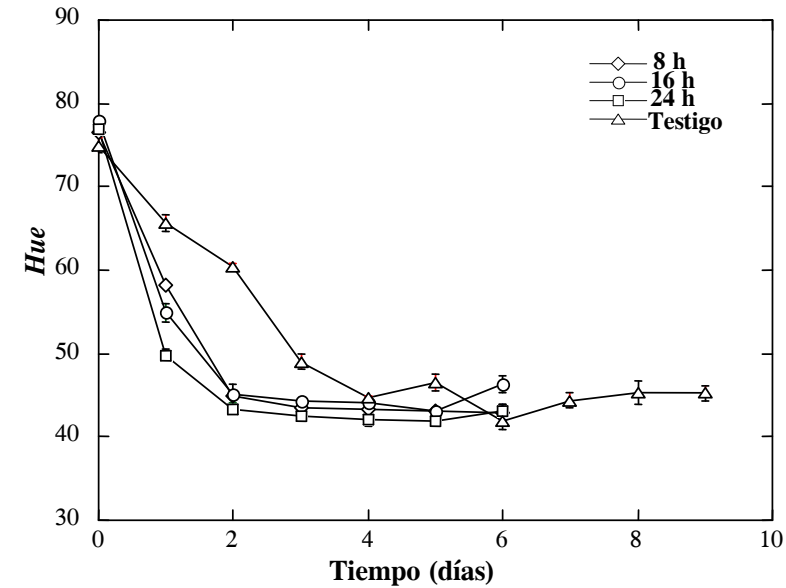

Figura 4. Efecto de la maduración acelerada a $25{ }^{\circ} \mathrm{C}$ en atmósfera modificada con $500 \mu \mathrm{L} \mathrm{L}^{-1}$ de etileno por 8, 16 ó 24 h de exposición, sobre el desarrollo del color (Hue) en la piel del fruto de papaya 'Maradol'.

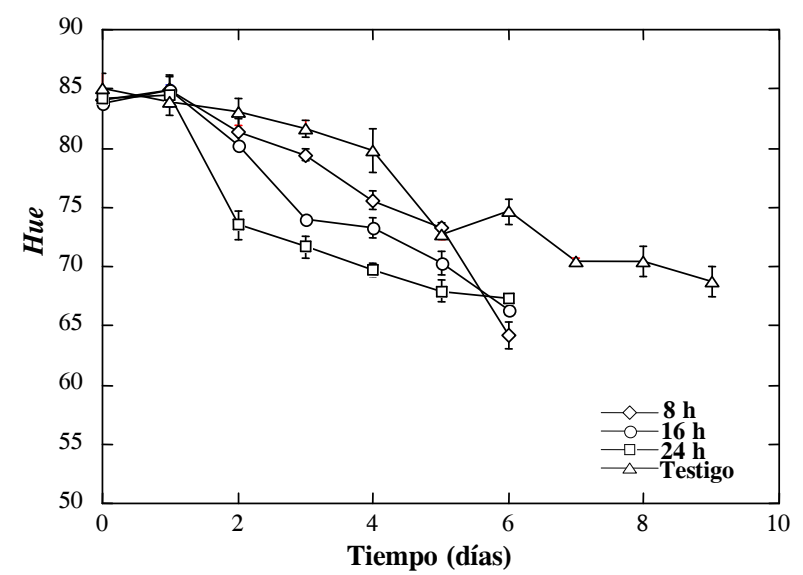

Figura 5. Efecto de la maduración acelerada a $25{ }^{\circ} \mathrm{C}$ en atmósfera modificada con $500 \mu \mathrm{L} \mathrm{L}^{-1}$ de etileno por 8, 16 ó $24 \mathrm{~h}$ de exposición, sobre el desarrollo del color $(\mathrm{Hue})$ en la pulpa del fruto de papaya 'Maradol'.

\section{CONCLUSIONES}

El contenido de ACC y la actividad de ACC oxidasa se incrementaron hasta $2.7 \mathrm{nmol}$ de $A C C \mathrm{~g}^{-1} \mathrm{~h}^{-1}$ y $3 \mathrm{~nL}$ de etileno $\mathrm{g}^{-1} \mathrm{~h}^{-1}$, respectivamente, como consecuencia del tratamiento con etileno correspondiente a $500 \mu \mathrm{L} \mathrm{L} \mathrm{L}^{-1}$, durante $24 \mathrm{~h}$. Los mejores resultados encontrados en esta investigación correspondieron a los tratamientos expuestos a $500 \mu \mathrm{L} \mathrm{L}^{-1}$ durante $24 \mathrm{~h}$, en el que los frutos mostraron un mejor desarrollo de color (Hue) y un ablandamiento rápido de la pulpa, determinado por la firmeza de la pulpa y el mayor contenido de sólidos solubles. Se logró adelantar la maduración de los frutos de papaya por $5 \mathrm{~d}$, cuando fueron expuestos a una atmósfera con $500 \mu \mathrm{L} \mathrm{L}^{-1}$ de etileno durante las $24 \mathrm{~h}$ previas a su almacenamiento a $25{ }^{\circ} \mathrm{C}$. Así en $3 \mathrm{~d}$ se alcanzaron las condiciones óptimas de consumo de los frutos, sin evidenciar daño por etileno, mientras que los frutos madurados bajo condiciones normales adquirieron estas características hasta el octavo día de almacenamiento.

\section{BIBLIOGRAFÍA}

Abeles F B, P W Morgan, M E Salveit (1992) Ethylene in Plant Biology. Vol. 15, 2nd ed. Academic Press. San Diego, California. pp:100-120.

AOAC Asociation of Official Analytical Chemists (1990) Official Methods of Analysis, 13th. Ed. Washington, D.C.

Chan-Jr H T (1979) Sugar composition of papayas during fruit development. HortScience 14:140-141.

Chan-Jr H T, S Y T Tam, S T Seo (1981) Papaya polygalacturonase and its role in thermally injured ripening fruit. J. Food Sci. 46:190197.

De La Cruz M J, Ramírez G P, H S García (2007) Estudio del efecto de la maduración acelerada y la refrigeración sobre la fisiología de la papaya Maradol (Carica papaya L). In: V Congreso Iberoamericano de Tecnología Postcosecha y Agroexportaciones. Universidad Politécnica de Cartagena, España. 29 de Mayo al 1 de Junio del 2007 pp:199-206.

Dong J G, J C Fernández-Maculet, S F Yang (1992) Purification and characterization of 1-aminocyclopropane-1-carboxylate oxidase from apple fruit. Proc. Natl. Acad. Sci. USA 89:9786-9793.

Fernández-Maculet, J C, J G Dong, S F Yang (1993) Activation of 1aminocyclopropane-1-carboxylate oxidase by carbon dioxide. Biochem. Biophys. Res. Comm. 193:1168-1173.

Hamilton A C, G W Lycett, D Grierson (1990) Antisense gene that inhibits synthesis of the hormone ethylene in transgenic plants. Nature 346:284-287.

Hamilton A C, M Bouzayen, D Grierson (1991) Identification of a tomato gene for the ethylene-forming enzyme by expression in yeasts. Proc. Natl. Acad. Sci. USA. 88:7434-7437.

Kader A A (1986) Biochemical and physiologycal basis for effects of controlled and modified atmospheres on fruits and vegetables. Food Technol. 5:99-105.

Kader A A (2002) Papaya. Recommendations for maintaining postharvest quality. Department of Pomology, University of California, Davis, California. USA. Disponible en: http://postharvest.ucdavis.edu/Produce/ProduceFacts/Espanol/Papay a.shtml (Febrero 2010)

Kende H (1993) Ethylene Biosynthesis. Annu. Rev. Plant Physiol. Plant Mol. Biol. 44:283-307.

Lizada M C, S F Yang (1979) A simple and sensitive assay for 1amino-cyclopropane-1-carboxylic acid. Analyt. Biochem. 100:140145 .

Lizada M C (1993) Mango. Biochemistry of Fruit Ripening. Chapman and Hall, London. pp:255-271.

Marangoni A G, R L Jackman, D W Stanley (1995) Chillingassociated softening of tomato fruit is related to increased pectinmethylesterase activity. J. Food Sci. 60:1277-1281.

NOM Norma Oficial Mexicana (1982). (NOM-FF-014-1982). Productos alimenticios no industrializados para consumo humano (fruta fresca). Determinación de la resistencia a la penetración. Diario Oficial del 10 de Junio de 1982.

Pantástico E B (1979) Fisiología, Postrecolección, Manejo y Utilización de Hortalizas y Frutos Tropicales y Subtropicales. 2a ed. Ed. Continental. México D. F. pp:29-50.

Paull R E, N J Chen (1983) Postharvest variation in cell wall-degrading enzymes of papaya (Carica papaya L.) during fruit ripening. Plant Physiol. 72:382-385.

Saltveit M E (1999) Effect of ethylene on quality of fresh fruits and vegetables. Postharv. Biol. Technol. 15:279-292. 
Tonutti P, C Bonghi, A Ramina (1993) Ethylene biosynthesis and kiwifruit following different postharvest treatments. Adv. Hort. Sci. 7:149-151.

Ververidis P, P John (1991) Complete recovery in vitro of ethyleneforming enzyme activity. Phytochemistry. 30:725-727.

Wills R B H, S B Widjanarko (1995) Changes in physiology, composition and sensory characteristics of Australian papaya during ripening. Australian J. Exp. Agric. 35:1173-1176.
Yang S F (1987) The role of ethylene and ethylene synthesis in fruit ripening. In: W W Thomson, E A Nothnagel, R C, Huffaker, (eds). Plant Senescence: Its Biochemistry and Physiology. The American Society of Plant Physiologists. 156-166. 